\title{
Assessment of Biomass Energy Sources in Electricity Generation Using Analytic Network Process Method
}

\author{
Mojtaba Safari ${ }^{1}$, Fatemeh Joghataee ${ }^{2} \&$ Mahtab Afsari ${ }^{3}$ \\ ${ }^{1}$ Faculty of management, University of Tehran, Tehran, Iran \\ ${ }^{2}$ Kharazmi University, Tehran, Iran \\ ${ }^{3}$ iPeG institute, University of Hannover, Germany \\ Correspondence: Mojtaba Safari, Faculty of management, University of Tehran, Tehran, Iran. Tel: \\ 98-912-602-3106. E-mail: m_safari@ut.ac.ir
}

Received: May 16, 2016

Accepted: June 18, $2016 \quad$ Online Published: September 30, 2016

doi:10.5539/mas.v11n1p23

URL: http://dx.doi.org/10.5539/mas.v11n1p23

\begin{abstract}
The purpose of this Paper is to assess and select the preferable and optimum biomass energy source using Analytic Network Process (ANP) for making an efficient Policy in Iran electricity generation industry. There are four major biomass energy sources in Iran comprising agriculture and forest wastes, biodegradable municipal waste, animal manure, and Municipal and industrial wastewater. In this paper, we assess and compare these resources, systematically, based on different Criteria and Sub-criteria derived from literatures and expert's views to choose the most preferable biomass source for producing required fuel for power plants. The required data will be gathered from experienced experts in Iran Renewable Energy Organization (SUNA). Results show that the criterion "economic and legal factors" has the highest importance (weight) among other identified criteria used in biomass source assessment. In addition, "biodegradable municipal waste" recognized as the most preferable biomass energy source for generating electricity in Iran power plants.
\end{abstract}

Keywords: Analytic Network Process (ANP), Biomass Energy, Electricity Generation, Fossil Fuel, Policy Making, Renewable Energy Sources

\section{Introduction}

Energy crisis and limitation, and environmental pollution of fossil fuel sources have caused different countries to pay attention to renewable energies including biomass as a secure, sustainable and clean energy source (Shahinfar et al., 2010). Biomass is a type of Renewable Energy Sources (RES), however it largely differs from other renewable sources. Biomass cannot be just called a source, but it comprises a large number of products needed to be classified for having more information about them (Ozcan, Öztürk, \& Oguz, 2015). Biomass energy sources which are suitable for generation of energy encompass a wide range of materials such as agriculture and forestry wastes, biodegradable municipal waste, animal manure, and urban and industrial wastewater (Boyle, 2004). Although different types of the biomass sources have the same form and appearance, they have a substantial diversity in physical and chemical properties which has beneficial in use of them as fuel. Today, we can find numerous technologies to convert and exploit the biomass energy from final products. Basically, the selection of biomass conversion technology is affected by three factors including access to raw nutrients, final application, and cost. Developing new and efficient technologies even without any increase in raw materials can aid us to generate energy through biomass more than before. Development trend in biomass technologies can be followed by substantial environmental, social and economic benefits (Abdoli et al., 2010).

The amount of energy biomass generation in developing countries is considerable. Africa, southern America and Asia provide $36.8 \%, 23.7 \%$, and $10.9 \%$ of total generated energy through biomass, respectively. However the biomass energy is not a significant energy source in industrial countries. Demand for biomass energy as an alternative for fossil energy sources keeps increasing due to the reduction of fossil sources as well as environmental limitations for fossil fuels and its acquiring better situation in organic fuels energy market. With regard to the statistics in 2010, Japan, China and India have been pioneers in this area and Japan has generated about 10 terawatt hours of electricity through fuels derived from biomass energy sources. Further, China with a growth about $25 \%$ has reached the production capacity by four gigawatts $(\mathrm{GW})$. India has reached to three 
gigawatts (GW) by adding 0.3 gigawatts (GW) to capacity of its biomass power plants by the end of 2010 (Otadi, Ahmadpoor, \& Yousefi, 2012). Iran with numerous cultivation areas for products has a high potential for generation of biomass. Unfortunately, however, governmental entities and authorities have not paid a particular attention to extraction, processing and exploitation these potential sources to generate energy, because there are no cohesive and integrative policies made for generation of energy through RES, especially biomass, in Iran.

To eliminate the shortcoming and make a suitable policy for biomass energy, this research aims to identify the potential sources using in biomass fuel production and determine evaluation criteria to measure and rank the sources, effectively. The next sections of the study are organized as follows:

Firstly, we represent the literature about biomass energy and its role in supplying fuel and generating electricity in power plants. Moreover different types of the biomass sources and their evaluation criteria will be described. After that, the proposed methodology is presented in detail based on Analytic Network Process (ANP) to evaluate the biomass sources and the data collected from experts are analyzed. The final section will address the main conclusions and discussion that may be drawn from this paper.

\section{Theoretical Framework}

Recent studies and future analyses on future use of fossil fuels have indicated that identification and replacement of fossil fuels with sustainable energy sources are required due to reduction of fossil fuel reserves and increase of greenhouse gases. Due to increased level of human demand for energy and limitation of oil reserves, it requires linking a bridge to use renewable energy sources so as to fill this gap, because the world will face the serious problem to supply fossil energies by 2020 with point of view of energy experts and suppliers of oil (Ekpenim et al., 2014). Energy supply through renewable energy sources will lead to increased sustainable development in countries. Hence, investigation into proposed strategies for energy exploration will be of great importance in future stability of the world (Kothari, Tyagi, \& Pathak, 2010). Among renewable energy sources, biomass energy seems pioneer than other sources, because it is found in most countries at different geographical locations and climate conditions. Biomass as a source for energy generation has been drawn into attention by many governments around the world (De Wit, Londo, \& Faaij, 2011; Scarlat et al., 2011; Yusaf, Goh, \& Borserio, 2011).

This issue has led to renewable raw materials have not been in competition with food crops, not resulting in carbon poverty and negative environmental effects. The reason for this can be easy access to agriculture wastes. These sources are supplied through agriculture products and their wastes and other wastes such as municipal solid waste, animal waste, and remaining wastes from food production process. Renewable sources of biomass as a sustainable energy sources with high potential have a potential role in supplying energy needs of industrialized countries and developing countries (Murtala, Aliyu, \& Babagana, 2012).

Li et al. (2008) in a study indicated more comprehensive studies in diversification of sources of biomass energy and announced that forest, agricultural and marine resources can be used as raw materials in the production of diverse biofuels such as bio-hydrogen, bio-oil, biodiesel, biogas and bi- methane. Nowadays, one of the contentions about the production of energy from biomass sources is related to processing biomass fuel through agriculture wastes and products. Due to growth of the world's population which has passed 7 Milliard people, this means that the need to allocate more land to agriculture and food production is required by the population. Hence, allocation of agricultural lands for generation of energy products can be a threat to the world, jeopardizing world food security. Hence, it is necessary to have a broader agricultural industry system so that extraction and supply of biofuels from this source be a part of that system.

In addition to this issue, Raman \& Mohr (2014) in their article "Bio fuels and the role of space in sustainable innovation journeys" have known opposition to legal principles of allocation of land to supply biomass fuel source and advantages of this source discussed by custodians and authorities.

According to related studies, development of renewable energy sources has been considered with five goals as follows (Cannemi et al., 2014):

- Reduce greenhouse gas emissions

- Increasing domestic and internal production to achieve self-efficacy at energy area

- Development of energy industry

- Create sustainable jobs

- Reduction of dependency on fossil fuels 


\subsection{Necessity and Advantages to Use Biomass Energy in Country}

The use of biomass as an energy source not only for economic reasons but also due to reasons including a social and environmental development is attractive. The systems which convert biomass into a consumable energy can act in small capacities in an efficient way. Agriculture and forestry industries are of main biomass reserves that provide substantial opportunities for economic development in rural and remote regions. Amount of emission of pollutants caused by combustion of biomass is generally less than amount of emission of pollutants from fossil fuels. In addition, commercial exploitation of biomass energy can remove or reduce the problems about disposal of waste in other industries including forestry and wood products, processing food and municipal solid waste in urban centers (Abdoli, Pazki, Fallahnejad, \& Samei, 2010).

Some of the advantages of biomass energy to replace fossil fuels can be characterized as follows (Otadi, Ahmadpoor, \& Yousefi, 2012; Sidighi et al., 2013):

- Resolving environmental problems caused by release of biomass sources in environment (water pollution, air, soil, etc.), because biofuels have a substantial potential for adjustment with environment.

- Reducing greenhouse gas emissions especially methane in the atmosphere (more than $50 \%$ emission methane is from this source), because these fuels have a carbon dioxide cycle in the combustion process, whereby amount of greenhouse gas emissions is severely reduced.

- Energy generation possibility at consumption area (reduction of wastes of network)

- Delivery possibility of clean energy in solid, liquid and gas forms

- Delivery possibility of energy in form of electricity, heat and fuel of automobiles and/or feed of petrochemical units

- Creation of value added and significant employment

- Controlling and processing 25 million tons of municipal solid and industrial waste and over 5 Milliard $\mathrm{m}^{3}$ of municipal and industrial wastewater

- Helping for general health improvement

- $\quad$ Energy generation with high availability

- Development of new market for agriculture products through production of these fuels

- Reduction of fossil fuels consumption by means of generation of these fuels

- Generation of a variety of fuels from biomass

\subsection{Status of Biomass Energy in Supply of Fuel at Power Plants and Electricity Generation}

Biomass has been used as a thermal-energy carrier directly in supply of thermal energy and light, mentioned that it can be transformed to electricity via suitable motor generators. In addition to supply of the required energy of country, development of biomass power plants can come effective in resolving the huge crisis due to household wastes and different environmental organic pollutants such as solid and liquid pollutants followed by substantial economic and social outcomes, under which this potential renewable energy source cannot be simply neglected in energy macro decision makings and municipal solid waste management and recycling solutions. Access to cheap energy sources in Iran has been considered as a serious barrier in trajectory of research and development of biomass power plants. But, considering environmental problems due to organic wastes and excessive cost considered for collection and disposal of them as well as considering the real energy price and value of oil products indicate that attention to biomass power plants in addition to suitable environmental outcomes besides energy generation has had the aspect for job creation, mentioned as a suitable alternative for oil products (Shahinfar et al., 2010). With regard to statements of Demirbas et al. (2009), processing and using biomass energy to supply fuel at power plants require development of technology and allocation of capital. In general, financing biomass power plants can be made through two ways. One of these ways is financing by owners of biomass sources and the other is acquisition of capital by domestic and foreign investors (Couture \& Gagnon, 2010).

\subsubsection{Origin of Biomass Power Plants}

Numerous organizations throughout the world try to consider more economic methods for improvement of efficient use of biomass in electricity generation process. Currently, the amount of electricity produced from biomass than existing biomass energy is negligent. This brings us to this question that if there is such tendency to use biomass energy to supply electricity power plants, why no speed is seen in development of these industries; 
it can give to fundamental responses to this question: firstly, any electricity power plant which works out with biomass fuel must compete with electricity power plants which work out with other fuels. In most of cases, use of fossil fuels can be our only choice to feed electricity power plants, because supply of energy by means of fossil fuels is more economic. Use of fossil fuels has been mentioned with more reliability in which the latest art technology of electricity power plants has been used with this capability that its equipment can be installed easily and rapidly and it also can be made in micro and macro sizes. Further, conventional fossil fuels are abundant, having low price in most of countries throughout the world. Secondly, biomass electricity power plants have relied on technology of steam turbines which have low yield, and mentioned with high price for installation of such power plants. As fossil equipment is larger in these power plants, there are different problems for burning and starting to work in them than fossil fuels (Shahinfar et al., 2010).

\subsubsection{Evaluation into Different Types of Major Biomass Sources}

Although different types of biomass have common forms and appearances, a substantial diversity can be observed in their physical and chemical properties. In general, all types of biomass with major constituents of carbohydrates, proteins, fats and cellulose can be considered as a digester feeding in anaerobic process. Major raw sources for bio-gas production are as follows:

- Agricultural and forestry waste and debris

- $\quad$ Livestock waste

- Biodegradable municipal waste

- Municipal and industrial wastewater

\subsubsection{Agricultural and Forestry Wastes}

Agricultural and forestry wastes include grain clippings, industrial plants wastes, vegetables wastes, fruit wastes, wastes from plantation forests, wastes from forestry products and wood industries (Abdoli et al., 2010). Agricultural wastes include husk, stalks, skins, weeds, crops straw and can be divided into two groups including harvest wastes which remain in land after harvesting such as flax stems and wastes from agricultural operations such as rice bran. The history of the use of wastes as fuel might conform the use of the agricultural product accounted as important fuel sources until now. Further, agricultural wastes are targeted in supplying fuel of numerous numbers of industries pertaining to agricultural processes, e.g. bagasse serves as fuel in process of production of sugar.

\subsubsection{Domestic Wastes}

Domestic wastes can be produced from the animals such as cattle, sheep, goats, cattle and sheep, horses, donkeys, mules, and camels. Domestic wastes from chicken, pig and cow have been mentioned as the most common wet wastes in Europe and some developing countries, especially in countries such as Netherlands and Denmark in which there is little space for spread of these wastes. Domestic wastes alone or combined with agricultural wastes and plant residuals or wastewaters of food industries can be subjected to anaerobic digestion process and be used as a biomass fuel source. Nowadays, via adding a supplementary food to this source, biogas generation is proliferated (Alvarez, Villca, \& Lidén, 2006).

\subsubsection{Biodegradable Municipal Waste}

Biodegradable municipal wastes include municipal solid waste. Municipal solid wastes, among which the only biodegradable type is the biodegradable organic wastes, are obtained through commercial, administrative, household operations and other industries. Hence, before use of these wastes in anaerobic digestion process, inorganic components must be separated from these wastes. Amount of biodegradable wastes in municipal solid wastes depends on different factors including production area, type of climate, culture, and progress of technology.

\subsubsection{Municipal and Industrial Wastewater}

Municipal liquid wastes from human settlements have a substantial energy that can be fermented in an anaerobic way likewise animal wastes producing methane. Anaerobic fermentation of wastewaters has been being implemented for several years, and since a long time ago, a large part of gas produced in generators and energy supply has been being produced for street lighting. In most of regions throughout the world, the gas produced to provide the required energy for cooling digesters is used in curing facilities, or it can be used to move engine of a generator to generate the required electricity of facilities (Kinoshita et al., 1997). 


\subsection{The Criteria for Evaluation and Selection of Biomass Sources}

With regard to the investigations into the related works, three major classifications for evaluation and selection of biomass sources include legal and economic, technical and environmental classifications, that each of these classifications includes some criteria which can affect evaluation and selection of biomass sources. These criteria include quantity of biomass source in the country, ratio of price / tonnage for curing sources and carriage to the area of use, ash disposal, government supports, industrial feasibility, combustion limitations, air and water pollution, access to processing technologies of biomass sources, suitable technical infrastructures to use biomass source for producing fuel (Ozcan, Öztürk, \& Oguz, 2015; Abdoli et al., 2010; Ekpeni et al., 2014; Cannemi et al., 2014). In following, each of the identified criteria is explained.

\section{- Quantity of biomass source in the country}

Quantity of biomass source in the country plays a key role in the preliminary studies as well as next functions for generation of biomass energy. Accordingly the main reason for neglecting energy generation projects from biomass lies on rise of problems in supply of fuel and change of its quality.

- Ratio of price / tonnage for curing sources and carriage to the area of use

The second criterion is the ratio of cost per ton of fuel which is carried to the area. The cost per ton of fuel can include the cost for processing in addition to the cost for carrying (transporting) to the area. The processing cost can be considered as an important factor in selection of biomass source.

\section{- Government supports}

Tax discounts and removal of legal limitations affect profitability of energy generation from biomass. In addition, in biomass fuel generation through agricultural products and wastes dependent on agricultural land, government's support in allocation of land to production of required raw materials and products in biomass energy can be of great importance.

\section{- Industrial feasibility}

Although industrial feasibility of conversion of biomass sources to useable heat and energy in industrial scale is a critical criterion, all the mentioned biomass sources have the ability for this conversion.

\section{- Combustion limitations}

Some biomass sources including agricultural products raise problems in process of combustion. Such limitations cause imposing additional costs. Combustion of wood wastes has the least limitation.

\section{- Air and water pollution}

In some places, use of biomass energy is profitable from environmental perspective. This includes reduction of greenhouse gas emission than fossil fuels. When biomass burns, little sulfur disseminates in the space and carbon dioxide returns to biomass production cycle. Further, use of biomasses from agricultural and forestry wastes cause reduction of forest fire. If principles of construction and design of combustion chambers are not taken into consideration, energy generation projects from biomass can raise pollution in environment. Concerning water pollution, it can be said that such pollution is not in substantial rate in biomasses from agricultural and forestry wastes. However, it is of great importance in biomasses from animal manure fertilizers. It should be noted that it is different in other biomass sources.

\section{- Ash disposal}

Combustion of major biomass sources raises producing ash, which is prevailed with numerous alkalinity due to existence of the criteria such as potassium, sodium, calcium and magnesium. Conventional methods for ash disposal such as landfill, in addition to having effect on land use, can be dangerous due to abrasive nature of ash criteria from environmental perspective.

- Access to processing technologies of biomass sources

Another effective criterion in selection of biomass energy source is access to processing technology of biomass sources. Some of biomass sources require advanced technology to be converted to fuel.

- Suitable technical infrastructures to use biomass source for producing fuel

Generation of biomass fuel has been regarded as the proposed source which requires sufficient knowledge, professional experts, and suitable technical facilities, which all can play potential roles in selection of the associated source regarding the existing facilities and infrastructures in country. 


\section{Methodology and Proposed Framework}

The present research is an applied research in terms of aim and a descriptive survey in terms of data collection method. The required information on detection of required data and criteria in determining their weight and ranking biomass energy sources have been collected through interview and distribution of questionnaire among 11 experts consisting specialized professors at the area of energy management and a number of managers and experts at Iran Renewable Energy Organization (SUNA). With regard to limited number of experts familiar with the area under discussion, purposive sampling has been considered in this research. Figure 1 represents the proposed framework of the present research to evaluate and to rank biomass energy sources step by step.

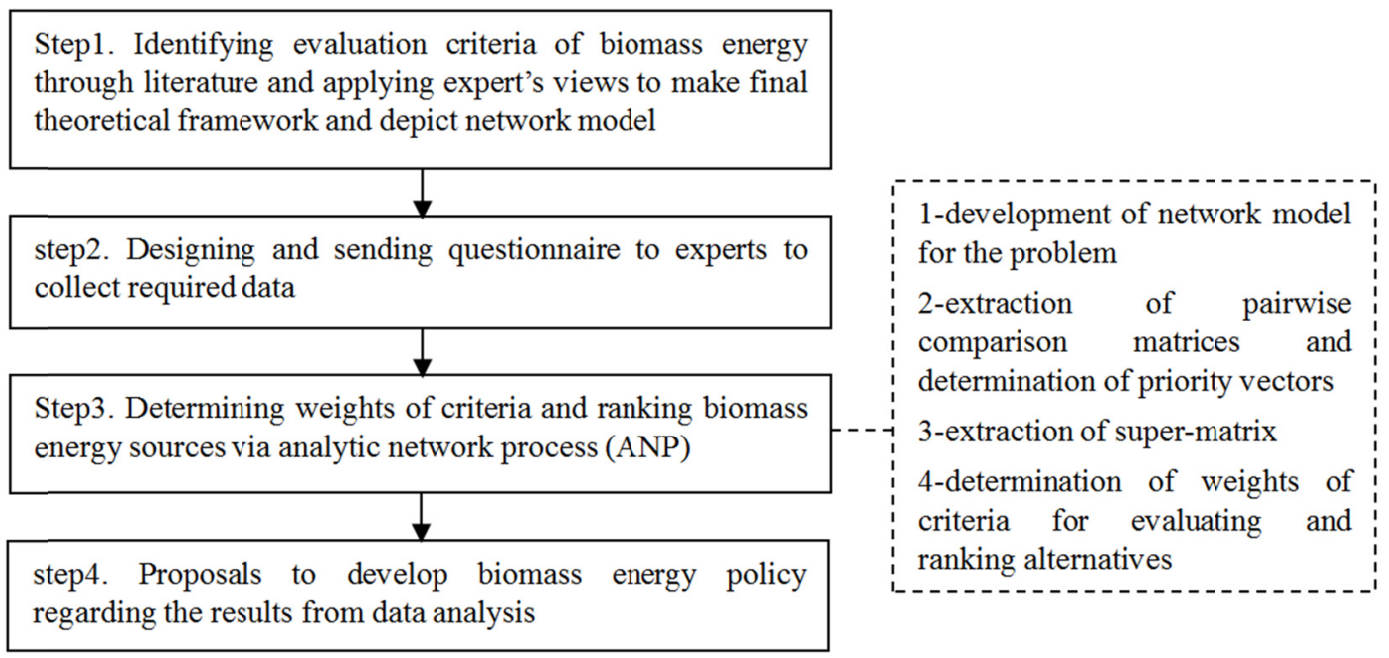

Figure 1. Proposed framework

Since the proposed model of research has been proposed focusing on analytic network process (ANP), thus analytic network process (ANP) is elaborated before discussing on the fourth section of research.

\subsection{Analytic Network Process (ANP)}

Analytic network process (ANP) refers to a comprehensive method for an accurate decision making via empirical information and/or personal judgments of any decision maker and facilitates decision making process through providing a structure for organizing different criteria and evaluating significance of each of them in alternatives. Analytic network process (ANP) has been developed from four major stages (Saaty, 2004):

1) development of network model for the problem

Problem must be described in a clear way and be analyzed to a network as a logic system. Structure of this network can be obtained by decision makers through brainstorming or other suitable methods.

2) extraction of pairwise comparison matrices and determination of priority vectors

Likewise the comparisons which are made in AHP, criteria of decision making pairs in each classification are compared regarding their significance. The groups are compared regarding their influence in goal via pairwise comparison. Decision makers are asked to give a response to a series of pairwise comparisons of two criteria in two groups so that their effect on criteria can be measured in higher levels. Effect of each criterion on other criteria can be displayed via eigenvector V. Amounts of importance are determined as table 1 which has been suggested by Mr. Saati. Score 1 represents quite equal priority or importance of two criteria and score 9 represents high priority or importance of one criterion compared to other criteria.

Table 1. Pairwise comparison of the criteria based on Saaty spectrum

\begin{tabular}{ll}
\hline Score & Importance of the criteria i in row toward the criteria j in column \\
\hline 1 & Quite equal priority or importance \\
3 & Low Priority or importance \\
5 & Middle Priority or importance \\
7 & High Priority or importance \\
\hline
\end{tabular}




\section{$9 \quad$ Very high Priority or importance}

$\underline{2,4,6,8 \quad \text { The median values }}$

A two-way amount is considered for inverse comparison in which $a_{i j}=1 / a_{i j}$ attributes to significance of criterion $i^{\text {th }}$ to $\mathrm{j}^{\text {th }}$. Likewise AHP method, pairwise comparisons in ANP is made in a matrix and a local priority vector (Vi) can be considered as estimation of significance associated to criteria and obtained via equation 1 .

$$
\text { A. } W=\lambda_{\max } * W
$$

In this equation, $\mathrm{A}, \mathrm{W}$ and $\lambda_{\max }$ represent pairwise comparison matrix, vector of weights and the largest weight vector of matrix A. Saati has suggested several algorithms for estimation W. in this research, pairwise comparison of matrices and determination of sustainability amounts are used to calculate weight vectors.

1) extraction of super-matrix

Super-matrix has the same concept as Markov chain process. To acquire general priorities in a system with independent effects, local priority vectors are embedded in the associated column in matrix. Indeed, super-matrix refers to a separated matrix in which each section indicates the relationship between two clusters in the system. Assume $\mathrm{K}=1,2,3, \ldots, \mathrm{n}, \mathrm{C}_{\mathrm{k}}$ represents the clusters in decision making system and each cluster $\mathrm{k}$ has $\mathrm{mk}$ criteria which are specified via $e_{k 1}, e_{k 2}, \ldots ., e_{k m k}$. Local priority vectors which had been acquired in the second stage have been classified and embedded in suitable positions in the super-matrix, which such embedment has been as chain based on the process of influence from a cluster to another cluster. Figure 2 represents a standard form of a super-cluster.

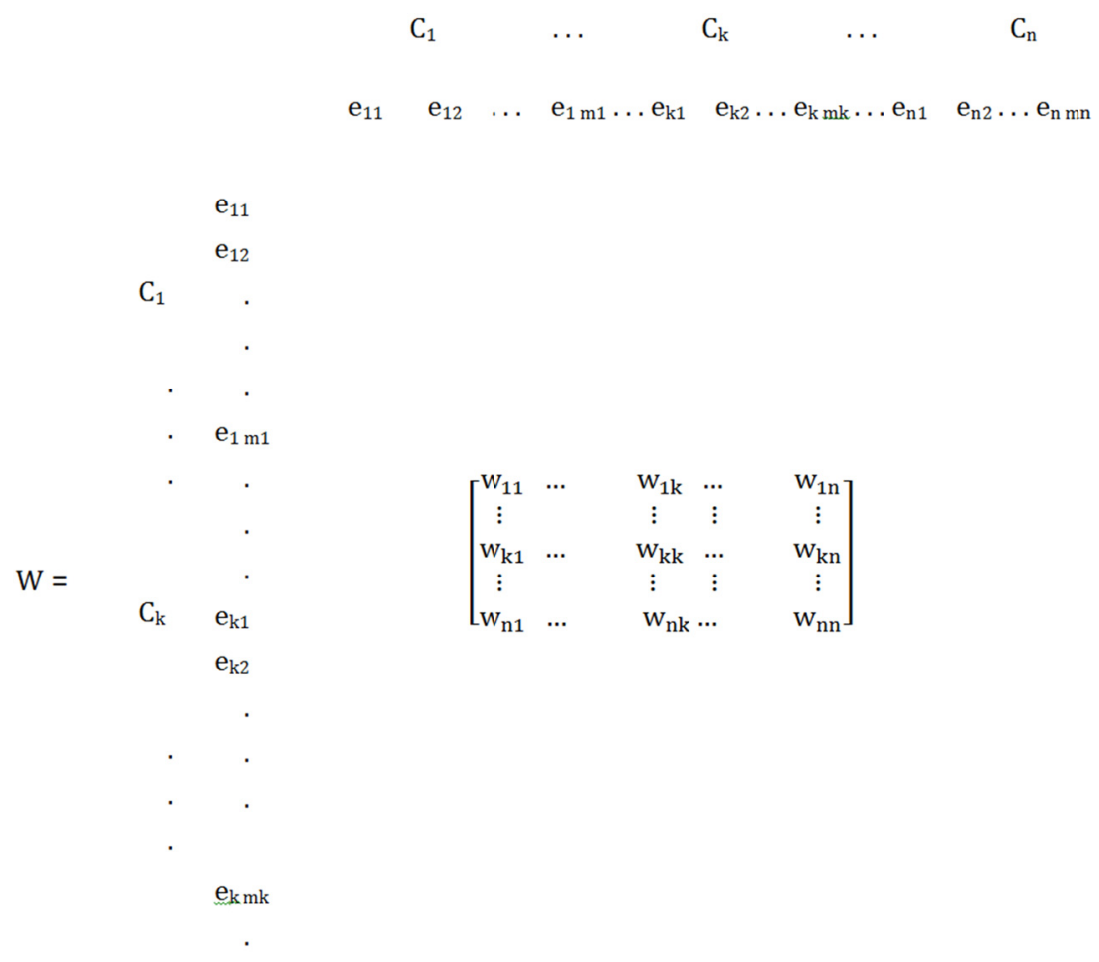

Figure 2. Standard form of a super-matrix

For instance, the super-matrix developed for a three-level hierarchal structure which is seen in figure 2 can be interpreted as follow. In this matrix, $\mathrm{W}_{21}$ refers to a vector which represents effect of goal level on criteria. $\mathrm{W}_{23}$ refers to a matrix that explains effect of criteria on alternatives. "I" represents "identify matrix" and 0 represents no influence of the associated criteria. Internal attachment has been represented via $W_{22}$ in super-matrix $W_{n}$. 


$$
\mathrm{W}_{\mathrm{n}}=\left[\begin{array}{ccc}
0 & 0 & 0 \\
\mathrm{w}_{21} & \mathrm{w}_{22} & 0 \\
0 & \mathrm{w}_{32} & \mathrm{I}
\end{array}\right]
$$

2) selection of the best alternative

If the super-matrix developed in step 3 spans the entire network, priority weights of alternatives can be found in the column for normalized super-matrix alternatives. In other words, if super-matrix had compared only the clusters with internal relationships, there will be need for future calculations to acquire general priorities of alternatives. The item with the highest final weight is the item which has been obtained via matrix operations and calculations. Hence, in summary, the proposed algorithm has eight steps to use ANP technique and matrix operations in determination of general priorities of alternatives.

Step 1. Determine the goal, criteria, sub-criteria and alternatives of problem

Step 2. Assume that there is no relationship among criteria, and then score the significance of challenge factors from 1 (Quite equal priority or importance) to 9 (very high Priority or importance)

Step 3. Using numerical scale ranging from 1 to 9 , specify matrix for interdependence among criteria regarding other criteria via schematic view and interdependence among criteria (calculation of W2).

Step 4. Specify the priority of interdependence among criteria, $\mathrm{W}_{\text {factors }}=\mathrm{W}_{1} * \mathrm{~W}_{2}$

Step 5. Specify the degree of local significance of secondary criteria using numerical scale ranging from 1 to 9 $\left(\mathrm{W}_{\text {Sub-factors (local) }}\right)$.

Step 6. Determine the degree of significance of secondary criteria via equation 3 :

$$
w_{\text {sub-factors(global) }}=\mathrm{w}_{\text {factors }} \times \mathrm{w}_{\text {sub-factors(local) }}
$$

Step 7. Specify the degree of significance of alternatives based on each secondary criterion using numerical scale ranging from 1 to 9 (calculation of W4).

Step 8. Calculate the final priority of alternatives based on interdependence among criteria using equation 4 .

$$
w_{\text {alternatives }}=\mathrm{w}_{4} \times \mathrm{w}_{\text {sub-factors }(\text { global })}
$$

\section{Data Analysis}

Giving response to a question that the researcher seeks from the beginning of research is the practical stage in a research. To achieve this, the collected data are analyzed. In this section, step-wise implementation of algorithm for the proposed model and data analysis are considered in order to determine weights of criteria and rank the biomass energy sources.

Step 1. Identifying evaluation criteria of biomass energy through literature and applying expert's views to make final theoretical framework and depict network model

At the first step, in addition to evaluation into the detected criteria, it requires considering related works and representing them to the experts to decide whether remove or purify the criteri and/or add new criteria to them. With representation of 9 criteria to the experts, all the criteria in the defined groups were confirmed and network structure developing goal, criteria, sub-criteria and alternatives was depicted as shown in figure 3.

Step 2. Designing and sending questionnaire to experts to collect required data

Since analytic network process (ANP) is used to evaluate and rank biomass energy sources in this research, it requires collecting the required data concerning priority of criteria and sub-criteria to each other. For this purpose, a questionaire was designed and distributed among 11 experts consisting of specialized professors at area of energy management and a number of managers and experts at Iran Renewable Energy Organization (SUNA). With regard to a prelimiary study which was conducted via collect data, it was specified that adjustment rate of pairwise comparison matrices which have been accomplished by the experts have been less than 0.1 , and this has confirmed reliability of questionaire.

Step 3. Determining weights of criteria and ranking biomass energy sources via analytic network process (ANP)

In step 3, with regard to the collected data in previous step, wieghts of the criteria are calculated and biomass energy sources are ranked via analytic network process (ANP). For this purpose, Super Decision software has been applied. It should be noted that final pairwise comparison matrices and inner dependence Matricses to enter into software and 
analysis have been taken from geometric mean of experts' views and the Inconsistency Index of all pairwise comparison matricses has been checked (Table 2-7). The amount of Inconsistency Index for all comparison matrices is lower than 0.1 that shows the reliability of all gathered data.

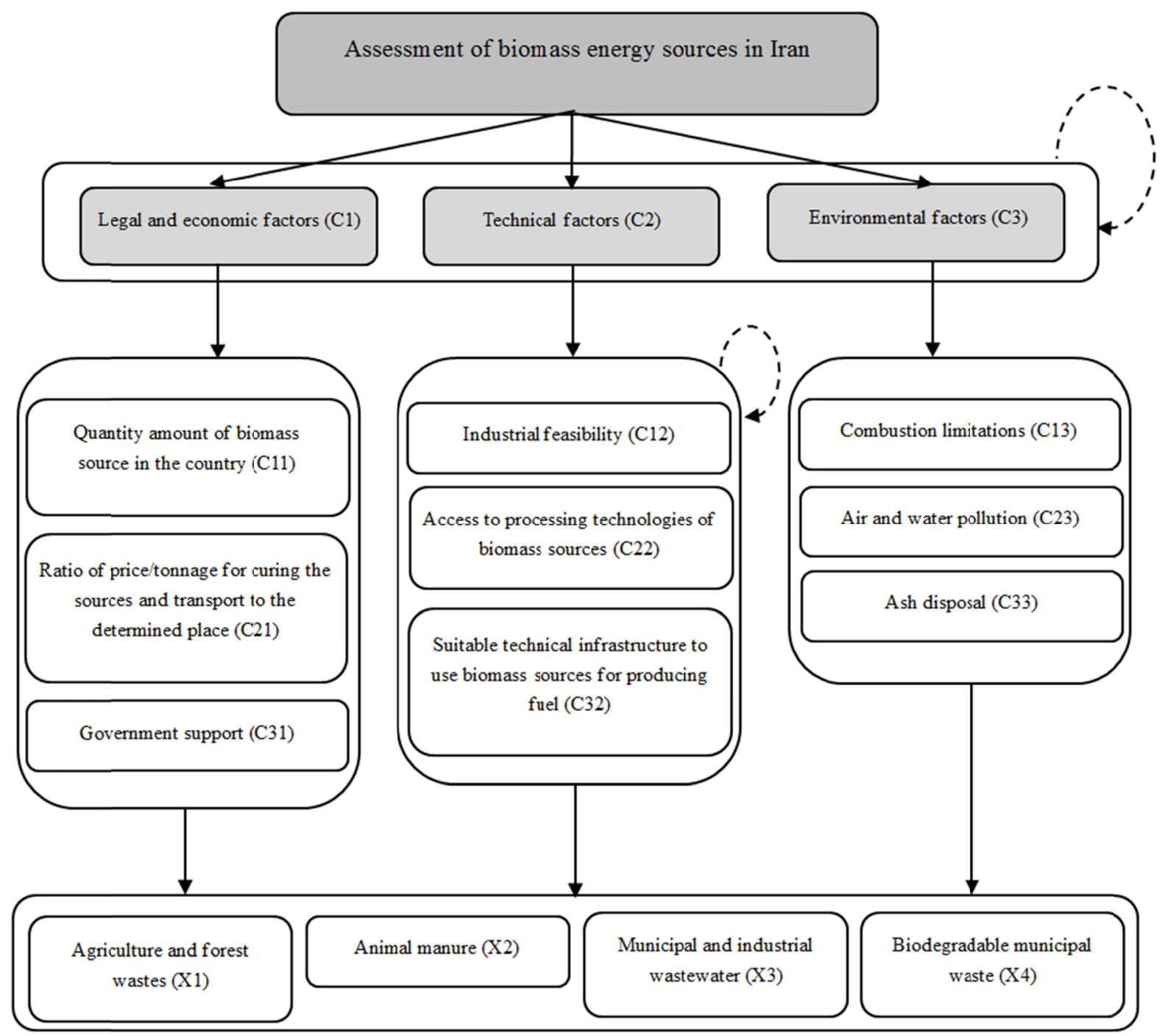

Figure 3. Network structure of the problem

Table 2. Pairwise comparison matrix of main criteria, regardless of dependence among them

\begin{tabular}{|c|c|c|c|}
\hline & $\mathrm{C} 1$ & $\mathrm{C} 2$ & $\mathrm{C} 3$ \\
\hline $\mathrm{C} 1$ & 1 & 1.75 & 1.4 \\
\hline $\mathrm{C} 2$ & & 1 & \\
\hline $\mathrm{C} 3$ & & 2.5 & 1 \\
\hline \multicolumn{4}{|c|}{ Inconsistency Index $=0.05$} \\
\hline
\end{tabular}

Table 3. Inner dependence Matricses of the main criteria

\begin{tabular}{lll}
\hline inner dependence according to C1 & $\mathrm{C} 2$ & $\mathrm{C} 3$ \\
\hline $\mathrm{C} 2$ & 1 & \\
$\mathrm{C} 3$ & 2.5 & 1 \\
Inconsistency Index $=0$ & & \\
inner dependence according to C2 & $\mathrm{C} 1$ & $\mathrm{C} 3$ \\
\hline
\end{tabular}




\begin{tabular}{lll}
\hline C1 & 1 & 1.7 \\
C3 & & 1 \\
Inconsistency Index =0 & & \\
inner dependence according to C3 & $\mathrm{C} 1$ & $\mathrm{C} 2$ \\
$\mathrm{C} 1$ & 1 & 2.3 \\
$\mathrm{C} 2$ & & 1 \\
Inconsistency Index $=0$ & & \\
\hline
\end{tabular}

Table 4. Pairwise comparison matrix of sub-criteria of the Legal and economic factors (C1)

\begin{tabular}{llll}
\hline & C11 & C21 & C31 \\
\hline C11 & 1 & & \\
$\mathrm{C} 21$ & 1.3 & 1 & 1.2 \\
C31 & 1.5 & & 1 \\
\multicolumn{4}{l}{ Inconsistency Index $=$} \\
\hline
\end{tabular}

Table 5. Pairwise comparison matrix of sub-criteria of the Technical factors (C2)

\begin{tabular}{llll}
\hline & $\mathrm{C} 12$ & $\mathrm{C} 22$ & $\mathrm{C} 32$ \\
\hline $\mathrm{C} 12$ & 1 & 1.3 \\
$\mathrm{C} 22$ & & 1 & \\
$\mathrm{C} 32$ & 1.6 & 1.2 & 1 \\
\multicolumn{4}{l}{ Inconsistency } \\
\multicolumn{4}{l}{}
\end{tabular}

Table 6. Pairwise comparison matrix of sub-criteria of the Environmental factors (C3)

\begin{tabular}{llll}
\hline & $\mathrm{C} 13$ & $\mathrm{C} 23$ & $\mathrm{C} 33$ \\
\hline $\mathrm{C} 13$ & 1 & & 1 \\
$\mathrm{C} 23$ & 1.8 & 1 & 1.5 \\
$\mathrm{C} 33$ & & & 1 \\
\multicolumn{4}{l}{ Inconsistency } \\
Index & $=0.003$ \\
\hline
\end{tabular}

Table 7. Inner dependence Matrix of the sub-criteria of the Technical factors (C2) according to Industrial feasibility (C12)

\begin{tabular}{lll}
\hline & C22 & C 32 \\
\hline C22 & 1 & 1.5 \\
C32 & & 1 \\
Inconsistency Index $=0$ \\
\hline
\end{tabular}

After computing the input data, the primary and weighted super-matrix were constructed as table 8 and 9 . 
Table 8. Primary super-matrix

\begin{tabular}{llllllllllllllllll}
\hline & $\mathrm{X}$ & $\mathrm{X}$ & $\mathrm{X}$ & $\mathrm{X}$ & $\mathrm{C} 1$ & $\mathrm{C} 2$ & $\mathrm{C} 3$ & $\mathrm{C} 1$ & $\mathrm{C} 2$ & $\mathrm{C} 3$ & $\mathrm{C} 1$ & $\mathrm{C} 2$ & $\mathrm{C} 3$ & $\mathrm{C} 1$ & $\mathrm{C} 2$ & $\mathrm{C} 3$ & Goa \\
& 1 & 2 & 3 & 4 & 1 & 1 & 1 & 2 & 2 & 2 & 3 & 3 & 3 & & & \\
\hline $\mathrm{X} 1$ & 0 & 0 & 0 & 0 & 0.3 & 0.2 & 0.2 & 0.1 & 0.1 & 0.2 & 0.2 & 0.1 & 0.2 & 0 & 0 & 0 & 0 \\
$\mathrm{X} 2$ & 0 & 0 & 0 & 0 & 0.1 & 0.4 & 0.1 & 0.2 & 0.4 & 0.2 & 0.3 & 0.1 & 0.1 & 0 & 0 & 0 & 0 \\
$\mathrm{X} 3$ & 0 & 0 & 0 & 0 & 0.3 & 0.1 & 0.4 & 0.3 & 0.2 & 0.2 & 0.1 & 0.4 & 0.3 & 0 & 0 & 0 & 0 \\
$\mathrm{X} 4$ & 0 & 0 & 0 & 0 & 0.2 & 0.1 & 0.1 & 0.2 & 0.2 & 0.2 & 0.2 & 0.3 & 0.2 & 0 & 0 & 0 & 0 \\
$\mathrm{C} 11$ & 0 & 0 & 0 & 0 & 0 & 0 & 0 & 0 & 0 & 0 & 0 & 0 & 0 & 0.2 & 0 & 0 & 0 \\
$\mathrm{C} 21$ & 0 & 0 & 0 & 0 & 0 & 0 & 0 & 0 & 0 & 0 & 0 & 0 & 0 & 0.3 & 0 & 0 & 0 \\
$\mathrm{C} 31$ & 0 & 0 & 0 & 0 & 0 & 0 & 0 & 0 & 0 & 0 & 0 & 0 & 0 & 0.3 & 0 & 0 & 0 \\
$\mathrm{C} 12$ & 0 & 0 & 0 & 0 & 0 & 0 & 0 & 0 & 0 & 0 & 0 & 0 & 0 & 0 & 0.3 & 0 & 0 \\
$\mathrm{C} 22$ & 0 & 0 & 0 & 0 & 0 & 0 & 0 & 0 & 0 & 0 & 0 & 0 & 0 & 0 & 0.2 & 0 & 0 \\
$\mathrm{C} 32$ & 0 & 0 & 0 & 0 & 0 & 0 & 0 & 0 & 0 & 0 & 0 & 0 & 0 & 0 & 0.4 & 0 & 0 \\
$\mathrm{C} 13$ & 0 & 0 & 0 & 0 & 0 & 0 & 0 & 0 & 0 & 0 & 0 & 0 & 0 & 0 & 0 & 0.2 & 0 \\
$\mathrm{C} 23$ & 0 & 0 & 0 & 0 & 0 & 0 & 0 & 0 & 0 & 0 & 0 & 0 & 0 & 0 & 0 & 0.4 & 0 \\
$\mathrm{C} 33$ & 0 & 0 & 0 & 0 & 0 & 0 & 0 & 0 & 0 & 0 & 0 & 0 & 0 & 0 & 0 & 0.2 & 0 \\
$\mathrm{C} 1$ & 0 & 0 & 0 & 0 & 0 & 0 & 0 & 0 & 0 & 0 & 0 & 0 & 0 & 0 & 0.6 & 0.7 & 0.43 \\
$\mathrm{C} 2$ & 0 & 0 & 0 & 0 & 0 & 0 & 0 & 0 & 0 & 0 & 0 & 0 & 0 & 0.2 & 0 & 0.3 & 0.19 \\
$\mathrm{C} 3$ & 0 & 0 & 0 & 0 & 0 & 0 & 0 & 0 & 0 & 0 & 0 & 0 & 0 & 0.7 & 0.3 & 0 & 0.38 \\
$\mathrm{Goa}$ & 0 & 0 & 0 & 0 & 0 & 0 & 0 & 0 & 0 & 0 & 0 & 0 & 0 & 0 & 0 & 0 & 0 \\
\hline
\end{tabular}

Table 9. Weighted super-matrix

\begin{tabular}{|c|c|c|c|c|c|c|c|c|c|c|c|c|c|c|c|c|c|}
\hline & $\begin{array}{l}\mathrm{X} \\
1\end{array}$ & $\begin{array}{l}\mathrm{X} \\
2\end{array}$ & $\begin{array}{l}\mathrm{X} \\
3\end{array}$ & $\begin{array}{l}X \\
4\end{array}$ & $\begin{array}{l}\mathrm{C} 1 \\
1\end{array}$ & $\begin{array}{l}\mathrm{C} 2 \\
1\end{array}$ & $\begin{array}{l}\mathrm{C} 3 \\
1\end{array}$ & $\begin{array}{l}\mathrm{C} 1 \\
2\end{array}$ & $\begin{array}{l}\mathrm{C} 2 \\
2\end{array}$ & $\begin{array}{l}\mathrm{C} 3 \\
2\end{array}$ & $\begin{array}{l}\mathrm{C} 1 \\
3\end{array}$ & $\begin{array}{l}\mathrm{C} 2 \\
3\end{array}$ & $\begin{array}{l}\mathrm{C} 3 \\
3\end{array}$ & $\mathrm{C} 1$ & $\mathrm{C} 2$ & C3 & $\begin{array}{l}\text { Goa } \\
1\end{array}$ \\
\hline $\mathrm{X} 1$ & 0 & 0 & 0 & 0 & $\begin{array}{l}0.3 \\
1\end{array}$ & $\begin{array}{l}0.2 \\
5\end{array}$ & $\begin{array}{l}0.2 \\
4\end{array}$ & $\begin{array}{l}0.1 \\
4\end{array}$ & $\begin{array}{l}0.1 \\
7\end{array}$ & $\begin{array}{l}0.2 \\
5\end{array}$ & $\begin{array}{l}0.2 \\
8\end{array}$ & $\begin{array}{l}0.1 \\
7\end{array}$ & $\begin{array}{l}0.2 \\
1\end{array}$ & 0 & 0 & 0 & 0 \\
\hline $\mathrm{X} 2$ & 0 & 0 & 0 & 0 & $\begin{array}{l}0.1 \\
1\end{array}$ & $\begin{array}{l}0.4 \\
4\end{array}$ & $\begin{array}{l}0.1 \\
6\end{array}$ & $\begin{array}{l}0.2 \\
4\end{array}$ & $\begin{array}{l}0.4 \\
1\end{array}$ & $\begin{array}{l}0.2 \\
7\end{array}$ & $\begin{array}{l}0.3 \\
1\end{array}$ & $\begin{array}{l}0.1 \\
1\end{array}$ & $\begin{array}{l}0.1 \\
2\end{array}$ & 0 & 0 & 0 & 0 \\
\hline $\mathrm{X} 3$ & 0 & 0 & 0 & 0 & $\begin{array}{l}0.3 \\
7\end{array}$ & $\begin{array}{l}0.1 \\
2\end{array}$ & $\begin{array}{l}0.4 \\
3\end{array}$ & $\begin{array}{l}0.3 \\
7\end{array}$ & $\begin{array}{l}0.2 \\
1\end{array}$ & $\begin{array}{l}0.2 \\
8\end{array}$ & $\begin{array}{l}0.1 \\
6\end{array}$ & $\begin{array}{l}0.4 \\
3\end{array}$ & $\begin{array}{l}0.3 \\
9\end{array}$ & 0 & 0 & 0 & 0 \\
\hline $\mathrm{X} 4$ & 0 & 0 & 0 & 0 & $\begin{array}{l}0.2 \\
0\end{array}$ & $\begin{array}{l}0.1 \\
9\end{array}$ & $\begin{array}{l}0.1 \\
7\end{array}$ & $\begin{array}{l}0.2 \\
5\end{array}$ & $\begin{array}{l}0.2 \\
2\end{array}$ & $\begin{array}{l}0.2 \\
0\end{array}$ & $\begin{array}{l}0.2 \\
5\end{array}$ & $\begin{array}{l}0.3 \\
0\end{array}$ & $\begin{array}{l}0.2 \\
8\end{array}$ & 0 & 0 & 0 & 0 \\
\hline C11 & 0 & 0 & 0 & 0 & 0 & 0 & 0 & 0 & 0 & 0 & 0 & 0 & 0 & $\begin{array}{l}0.1 \\
3\end{array}$ & 0 & 0 & 0 \\
\hline C21 & 0 & 0 & 0 & 0 & 0 & 0 & 0 & 0 & 0 & 0 & 0 & 0 & 0 & $\begin{array}{l}0.1 \\
9\end{array}$ & 0 & 0 & 0 \\
\hline C 31 & 0 & 0 & 0 & 0 & 0 & 0 & 0 & 0 & 0 & 0 & 0 & 0 & 0 & $\begin{array}{l}0.1 \\
8\end{array}$ & 0 & 0 & 0 \\
\hline $\mathrm{C} 12$ & 0 & 0 & 0 & 0 & 0 & 0 & 0 & 0 & 0 & 0 & 0 & 0 & 0 & 0 & $\begin{array}{l}0.1 \\
5\end{array}$ & 0 & 0 \\
\hline $\mathrm{C} 22$ & 0 & 0 & 0 & 0 & 0 & 0 & 0 & 0 & 0 & 0 & 0 & 0 & 0 & 0 & $\begin{array}{l}0.1 \\
4\end{array}$ & 0 & 0 \\
\hline C 32 & 0 & 0 & 0 & 0 & 0 & 0 & 0 & 0 & 0 & 0 & 0 & 0 & 0 & 0 & $\begin{array}{l}0.2 \\
0\end{array}$ & 0 & 0 \\
\hline $\mathrm{C} 13$ & 0 & 0 & 0 & 0 & 0 & 0 & 0 & 0 & 0 & 0 & 0 & 0 & 0 & 0 & 0 & $\begin{array}{l}0.1 \\
3\end{array}$ & 0 \\
\hline $\mathrm{C} 23$ & 0 & 0 & 0 & 0 & 0 & 0 & 0 & 0 & 0 & 0 & 0 & 0 & 0 & 0 & 0 & $\begin{array}{l}0.2 \\
3\end{array}$ & 0 \\
\hline $\mathrm{C} 33$ & 0 & 0 & 0 & 0 & 0 & 0 & 0 & 0 & 0 & 0 & 0 & 0 & 0 & 0 & 0 & $\begin{array}{l}0.1 \\
4\end{array}$ & 0 \\
\hline $\mathrm{C} 1$ & 0 & 0 & 0 & 0 & 0 & 0 & 0 & 0 & 0 & 0 & 0 & 0 & 0 & 0 & $\begin{array}{l}0.3 \\
2\end{array}$ & $\begin{array}{l}0.3 \\
5\end{array}$ & 0.43 \\
\hline C2 & 0 & 0 & 0 & 0 & 0 & 0 & 0 & 0 & 0 & 0 & 0 & 0 & 0 & $\begin{array}{l}0.1 \\
4\end{array}$ & 0 & $\begin{array}{l}0.1 \\
5\end{array}$ & 0.19 \\
\hline C3 & 0 & 0 & 0 & 0 & 0 & 0 & 0 & 0 & 0 & 0 & 0 & 0 & 0 & $\begin{array}{l}0.3 \\
6\end{array}$ & $\begin{array}{l}0.1 \\
9\end{array}$ & 0 & 0.38 \\
\hline $\begin{array}{l}\text { Goa } \\
1\end{array}$ & 0 & 0 & 0 & 0 & 0 & 0 & 0 & 0 & 0 & 0 & 0 & 0 & 0 & 0 & 0 & 0 & 0 \\
\hline
\end{tabular}

Weights of each of criteria and sub-criteria and priority of alternatives via two ways including existing priorities in super-matrix and normalized priorities in node were extracted through developing weighted super-matrix and limited super-matrix (Table 10). 
Table 10. Weights of each criterion and sub-criterion and priority of alternatives in limited super-matrix

\begin{tabular}{|c|c|c|c|}
\hline \multicolumn{4}{|c|}{ Here are the priorities. } \\
\hline Icon & Name & $\mid \overline{\text { Normalized by Cluster }}$ & Limiting \\
\hline$\overline{\text { Nolcon }}$ & $x 1$ & 0.22807 & 0.114034 \\
\hline Nolcon & $\times 2$ & 0.23940 & 0.119699 \\
\hline Nolcon & $\times 3$ & 0.30608 & $\longdiv { 0 . 1 5 3 0 4 2 }$ \\
\hline Nolcon & $\times 4$ & 0.22645 & $\longdiv { 0 . 1 1 3 2 2 5 }$ \\
\hline Nolcon & C11 & 0.26351 & 0.025571 \\
\hline Nolcon & $\mathrm{C} 21$ & 0.38184 & 0.037053 \\
\hline Nolcon & C31 & 0.35465 & 0.034415 \\
\hline Nolcon & $\mathrm{C} 12$ & 0.23496 & 0.016858 \\
\hline Nolcon & $\mathrm{C} 22$ & 0.35809 & 0.025692 \\
\hline Nolcon & C32 & 0.40695 & $\longdiv { 0 . 0 2 9 1 9 8 }$ \\
\hline Nolcon & $\mathrm{C} 13$ & 0.26621 & 0.023864 \\
\hline Nolcon & $\mathrm{C} 23$ & 0.45090 & $\longdiv { 0 . 0 4 0 4 2 0 }$ \\
\hline Nolcon & $\mathrm{C} 33$ & 0.28289 & 0.025359 \\
\hline Nolcon & $\mathrm{C} 1$ & 0.40170 & $\longdiv { 0 . 0 9 7 0 3 8 }$ \\
\hline Nolcon & $\mathrm{C2}$ & 0.22722 & 0.054890 \\
\hline Nolcon & C3 & 0.37108 & $\longdiv { 0 . 0 8 9 6 4 3 }$ \\
\hline Nolcon & Ranking BES & 0.00000 & 0.000000 \\
\hline
\end{tabular}

Ultimately, final ranking of each of alternatives is obtained based on Table 11.

Table 11. Results of alternative analysis

\begin{tabular}{|c|c|c|c|c|}
\hline Name & Graphic & Ideals & Normals & Raw \\
\hline X1 & & 0.745118 & 0.228069 & 0.114034 \\
\hline$x 2$ & & 0.782130 & 0.239398 & 0.119699 \\
\hline$\times 3$ & & 1.000000 & 0.306084 & 0.153042 \\
\hline$X_{4}$ & & 0.739828 & 0.226449 & 0.113225 \\
\hline
\end{tabular}

In Table 11, final status of four biomass energy sources is observed in three columns. Raw column represents the numers in limited super-matrix. Normal column represents normalized results in each node and Ideal column represents division of numbers in each of Normal or Raw columns on the largest value on the associated column. Findings indicate that X3 energy source (degradable municipal waste) has higher priority than other sources for conversion to a suitable biomass fuel at power plants.

Step 4. Proposals to develop biomass energy policy regarding the results from data analysis

With regard to the results from data analysis in previous step, it was observed that criterion of legal and economic factors among detected criteria enjoys higher wieght and signficance for decision making upon biomass energy source. This indicates that it requires paying a particular attention to legal and economic factors and their sub-criteria including government supports ratio of price / tonnage for curing sources and carriage to the area of use, and quantity of biomass source in the country. In addition, with regard to the results from evaluation of biomass energy sources by experts, it was specified that a higher priority has been given to degradable municipal waste, for which it requires considering strategies and policies at the area of biomass energy in line with use of degradable municipal waste and use of suitable infrastructures for better exploitation from these sources.

\section{Discussion and Conclusion}

The use of biomass sources for energy generation, and its gradual replacement with fossil fuels not only is an 
option but is considered as a basic necessity for achieving the goals of sustainable development .Because if there was the lack of access to clean energy, public health endangered. Despite the existence of unique and enriched natural resources, especially in the production of biogas, in Iran, unfortunately no major action has been done in order to accelerate the development of biomass energy. Accelerate the development of clean energy, especially biomass (according to the capabilities mentioned above), can be a fundamental solution to rid the country of pressure of economy dependent on fossil fuels, especially oil. According to the capability of biomass energy resources needed to produce electricity and heat as well as the availability of the variety spectrum of the resources in Iran, the existence of an efficient policy for orientation towards the use of these resources instead of fossil fuels is felt over before. In order for making an appropriate policy to produce electricity by using fuels derived from biomass resources, this study evaluated and prioritized biomass energy sources comprising agriculture and forestry wastes, biodegradable municipal waste, animal manure, and urban and industrial wastewater, using Analytic Network Process (ANP) method.

The results showed that among mentioned biomass sources in Iran, biodegradable municipal waste was of higher priority regarding to all the criteria. In other words, it may be considered as the best biomass source to produce required fuel for power plants. Accordingly, the government, authorities, and decision-makers can take primary steps in order to replace clean energy instead of fossil fuels by designing policy making model for biomass energy sources with a focus on biodegradable municipal waste. Use of biomass energy sources for electricity production in Iran requires a lot of work and a large amount of initial investment, which is certainly in need of state funding. In this context, the following recommendations are presented:

- $\quad$ Paying a special attention to R\&D on clean and renewable energy, particularly biomass.

- $\quad$ Funding for knowledge-based companies and science and technology parks for the acquisition of basic knowledge in this area.

- Government support to facilitate the production and import of technology, equipment and machinery related to the extraction and processing of biomass energy sources

- Supporting and organizing farmers and ranchers for production and storage of agricultural and livestock waste.

- $\quad$ Promote a culture of recycling by community members

- $\quad$ Providing special facilities to the industrial center to organize better industrial wastewater to assign it to produce biomass fuel.

\section{References}

Abdoli, M. A., Pazki, M., Fallahnejad, M. A., \& Samei Far, R. (2010). Evaluation and classification of biomass sources in Iran and the world, and investigation of their diversity in rural areas with emphasis on common solid waste and manure. Fifth National Conference on waste Management, Mashhad, Iran.

Alvarez, R., Villca, S., \& Lidén, G. (2006). Biogas production from llama and cow manure at high altitude. Biomass and Bioenergy, 30(1), 66-75. http://dx.doi.org/10.1016/ j.biombioe .2005.10.001

Boyle, G. (2004). Renewable Energy: power for a sustainable future (2nd Ed.). Oxford University Press.

Cannemi, M., García, M. M., Aragonés, B. P., \& Gómez, N. T. (2014). Modelling decision making as a support tool for policy making on renewable energy development. Energy Policy, 67, 127-137. http://dx.doi.org/10.1016/j.enpol.2013.12 .011

Couture, T., \& Gagnon, Y. (2010). An analysis of feed-in tariff remuneration models: Implications for renewable energy investment. Energy Policy, 38(2), 955-965. http://dx.doi.org/10. 1016/j.enpol.2009.10.047

De Wit, M., Londo, M., \& Faaij, A. (2011). Productivity developments in European agriculture: Relations to and opportunities for biomass production. Renewable and Sustainable Energy Reviews, 15(5), 2397-2412. http://dx.doi.org/10.1016/j.rser.2011.02.0 22

Ekpeni, L. E., Benyounis, K. Y., Nkem, E. F., Stokes, J., \& Olabi, A. G. (2014). Energy diversity through renewable energy source (RES)-a case study of biomass. Energy Procedia, 61, 1740-1747. http://dx.doi.org/10.1016/j.egypro.2014.12.202

Kinoshita, C. M., Turn, S. Q., Overend, R. P., \& Bain, R. L. (1997). Power generation potential of biomass gasification systems. Journal of Energy Engineering, $123(3), \quad 88-99$. http://dx.doi.org/10.1061/(ASCE)0733- 9402(1997)123:3(88)

Kothari, R., Tyagi, V. V., \& Pathak, A. (2010). Waste-to-energy: A way from renewable energy sources to 
sustainable development. Renewable and Sustainable Energy Reviews, 14(9), 3164-3170. http://dx.doi.org/10.1016/j.rser.2010.05.005

Li, Y., Horsman, M., Wu, N., Lan, C. Q., \& Dubois, C. N. (2008). Biofuels from microalgae. Biotechnology Progress, 24(4), 815-820. http://onlinelibrary.wiley.com/doi/10.1021/bp070371k/ full

Murtala, A. M., Aliyu, B. A., \& Babagana, G. (2012). Biomass resource as a source of sustainable energy production in developing countries. Journal of Applied Phytotechnology in Environmental Sanitation, 1(2), 103-112.

http://www.cabdirect.org/abstracts/20123317735.html;jsessionid=F41B604BFF6CDA48B7800C2DE BB0E9AC

Otadi, N., Ahmadpoor, A., \& Yousefi, M. (2012). Methods of producing energy from biomass. The third conference on bioenergy (biomass and biogas), Tehran, Iran.

Ozcan, M., Öztürk, S., \& Oguz, Y. (2015). Potential evaluation of biomass-based energy sources for Turkey. Engineering Science and Technology, an International Journal, 18(2), 178-184. http://dx.doi.org/10.1016/j.jestch.2014.10.003

Raman, S., \& Mohr, A. (2014). Biofuels and the role of space in sustainable innovation journeys. Journal of Cleaner Production, 65, 224-233. http://dx.doi.org/10.1016/j.jclepro .2013.07 .057

Saaty, T. L. (2004). Fundamentals of the analytic network process-Dependence and feedback in decision-making with a single network. Journal of Systems Science and Systems Engineering, 13(2), 129-157. http://link.springer.com/article/10.1007/ s11518-006-0158-y

Scarlat, N., Dallemand, J. F., Skjelhaugen, O. J., Asplund, D., \& Nesheim, L. (2011). An overview of the biomass resource potential of Norway for bioenergy use. Renewable and Sustainable Energy Reviews, 15(7), 3388-3398. http://dx.doi.org/10.1016/j.rser .2011.04.028

Shahinfar, R., Raufi, M. R., Heidari, M., Ma'moori, A., \& Parnian, M. (2010). A Study on electricity generation using biomass fuels. The first conference on bioenergy, Tehran, Iran.

Sidighi, H., Chitgar, C. O., Tangaki, H., \& Esfahani, M. R. (2013). The necessity of using biomass energy for sustainable development. Fifth conference on renewable, clean and efficient energy, Tehran, Iran.

Yusaf, T., Goh, S., \& Borserio, J. A. (2011). Potential of renewable energy alternatives in Australia. Renewable and Sustainable Energy Reviews, 15(5), 2214-2221. http://dx.doi.org/10.1016/j.rser.2011.01.018

\section{Copyrights}

Copyright for this article is retained by the author(s), with first publication rights granted to the journal.

This is an open-access article distributed under the terms and conditions of the Creative Commons Attribution license (http://creativecommons.org/licenses/by/4.0/). 